\title{
Drama in SPRACHPRAXIS at a German University English Department: Practical Solutions to Pedagogical Challenges
}

\author{
Jonathan Sharp
}

\begin{abstract}
This article describes the initial phase of incorporating drama-in-education classes into the practical language curriculum of a German university English department. It offers a brief overview of drama in (higher) education, before focusing on some recent developments in Germany and the UK: specifically the current increase of interest in Theaterpädagogik in Germany, and the incorporation of performative pedagogy in UK higher education, with the example of an initiative at the University of Warwick. The practical language curriculum of the University of Tübingen English Department, within which the drama classes are being run, is introduced. A report on one of the classes is provided, with a short example of a student-led presentation session. After investigating some student feedback from the class, the article concludes by suggesting that a drama approach offers solutions to some challenges posed by the curriculum, and explains a brief rationale for its further development in this context.
\end{abstract}

\section{Introduction: drama, theatre, process, product - a history of dichotomy}

The progress of drama in education over the past 50 years can in many ways be seen as a continuum of dichotomies. The work of early pioneers who brought plays to life in the literature classroom by acting them out with students paved the way for the recognition of the usefulness of drama in other subjects, an approach which started gathering speed from the 1970's in the work of Dorothy Heathcote and Gavin Bolton among others (cf. Bolton 1979). Thus the concept of 'process drama' was developed. This led to a first dichotomy: that between drama as a pedagogical tool applicable to other subjects, and drama as a school subject in its own right (cf. Hornbrook 1998). Subsequently it has been pointed out the two need not be mutually exclusive (cf. Fleming in Byram 1998); the tendency remains, however, to naturally emphasize one or the other depending on needs 
and context. The second dichotomy concerns output, and is best characterized by the distinction between the by-now common terms of drama-in-education (DiE) and theatre-in-education (TiE). In the former, the intended output has something to do with change effected in the participants and/or an immediate educational goal (see definitions of applied drama below), while in the latter the final 'product' is usually a kind of performance, with or without the presence of a paying audience. In terms of pedagogical methodology, DiE has been identified as an example of a "small-scale form", usually consisting of games and exercises easily incorporated into a single lesson, for example; while TiE has been categorized as comprised of "large-scale forms", often involving a longer-term rehearsal process in preparation for a final production or performance of some kind (Schewe 2013; 13-14). Recent work on drama-in-education in teacher training has started to emphasize the relevance of drama-in-education as a subject in its own right, and relevant to students' future careers (cf. Haack 2010; Haack/Surkamp 2011). In the Sprachpraxis (practical academic language) programme at the University of Tübingen English Department, this emerging 'subject' aspect of drama-in-education has special relevance in combination with a process approach applied to the specific pedagogical context. By using, and simultaneously investigating, drama-in-education with students, drama is once again doing its characteristic double duty, but with a twist: students practice and improve their spoken English through the familiar educational medium of drama, while learning more about the very field of drama-in-education itself, an area of immediate practical relevance to their future lives as teachers. This combinational methodology can be seen as an example of Tessa Woodward's 'Loop Input', "a specific type of experiential teacher training process that involves an alignment of the process and content of learning" (Woodward 2003: 301). Indeed the connection between process drama and experiential learning is mirrored in the connection between the combinational drama pedagogy I explore in this paper and loop input itself:

The advantages of loop input are that it is multi-sensory, in just the same way as experiential learning, but with the added advantage of involving self-descriptivity and recursion (Woodward 2003: 303).

The "self-descriptivity and recursion" of drama-in-education, as both process and subject in Sprachpraxis, represent the key to its pedagogical effectiveness in this case.

\section{DiE in higher education}

Although educational drama has a long history, especially in Britain, the main developments have tended to occur within school education. Only relatively recently, with a growing interest in the general pedagogical benefits of drama, has the scope of application been widened significantly. Even so, higher education, in particular university pedagogy, is an area still relatively untried in terms of drama approaches. One possible explanation is that educational 
drama, with its attendant emphasis on 'play', is perhaps seen as more naturally suitable for learning environments in which play is still an integral part; at university such models are perhaps viewed as inappropriate and/or superficial. In Germany and the UK, the countries on which this paper will focus, however, practitioners and scholars are starting to further exploit the holistic nature of drama as an educational technique.

Firstly, the recent growth of Theaterpädagogik (theatre pedagogy) as an organized area of training in Germany has emphasized breadth of application.

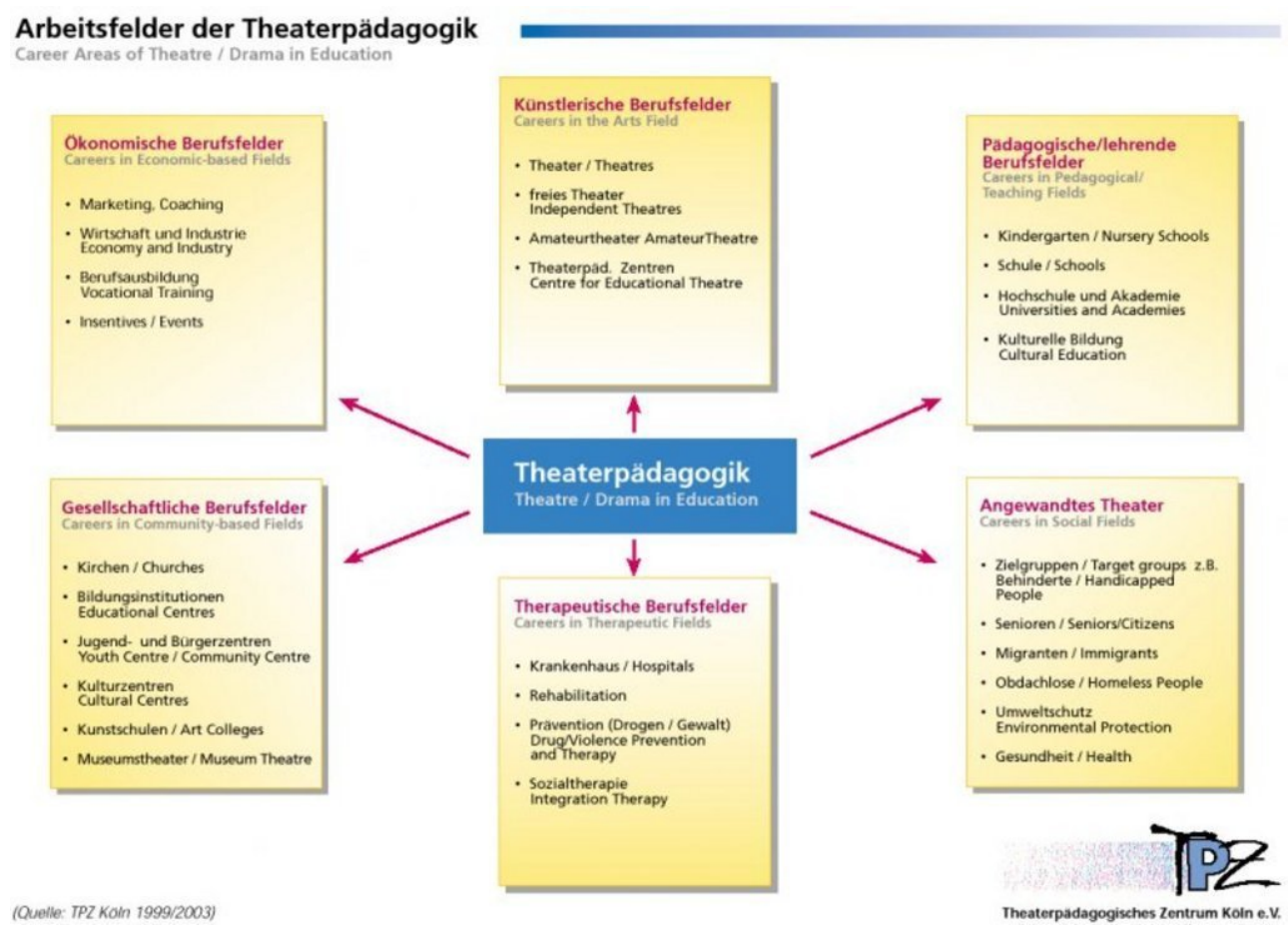

Figure 1: Berufsfelder Theaterpädagogik.

While a good deal of work in this area involves school education, including practitioners who work at professional theatres to provide educational workshops and programmes for school groups and teachers, there is an increasing recognition of the value of such work at higher educational level (cf. Fonio/Genicot 2011; Wildt et al. 2008). This trend is perhaps synonymous with the increased presence of the practical field Theaterpädagogik in university degree programmes (see 'Conclusions' below). There has also been a recent increase in practical training possibilities in this area, with the German Bundesverband Theaterpädagogik e.V. (Federal Association of Theatre Pedagogy) stressing the adaptability of the work to various contexts, with a focus nonetheless on theatre-based techniques and competencies:

In recent years theatre pedagogy has developed its own job profile. The work of a theatre pedagogue comprises artistic as well as pedagogical elements. The applications and focal points of the work are extremely ver- 
satile and wide-ranging, depending on whether the context is a theatre, a centre for theatre pedagogy or a college; or whether the work is focused in a communal, social or socio-pedagogical direction, or being practiced on a freelance basis (www. butinfo.de, my translation). ${ }^{1}$

From this description, the areas of social development and community-building generally seem to be emphasized; and indeed the university-based provision of Theaterpädagogik is normally integrated into educational studies such as teacher training, where the benefits of the approach are perhaps seen in a more general, less subject-specific light. This has much in common with Anglo-American applied theatre, with its socially committed heritage situated in the work of Augusto Boal (Boal 1985; 2002) amongst others. Recent descriptions have highlighted this, while underlining the essential importance of effect on the participants themselves:

... (applied drama is) dramatic work done for the benefit of the group $[\ldots]$ it is not concerned with making meaning for someone who is outside this process (as in a public audience) [...] a process-oriented means of exploring issues of concern to participants without the pressure of performance. (Prendergast and Saxton 2013: 1)

Here we can see clear parallels to the drama-in-education impulses which led on from more community-focused work in applied drama. In the classroom the participants are the students, and their "issues of concern", mediated and perhaps selected by the teacher, are the materials and concepts under investigation.

Another aspect shared by both Theaterpädagogik and applied drama traditions is the emphasis on process, also highlighted in the above quotations. The adaptability of this work clearly counts as a great strength, yet has simultaneously exposed the field/s to criticism on the basis of perceived imprecision and overgeneralization. Certainly at higher education level, where the emphasis arguably lies more on subject matter, the balance might tilt towards an increased focus on the literary/dramatic material. Nevertheless I would argue that in university Sprachpraxis at least, there is an almost perfect balance between the suitability of drama both as a vehicle for language learning and as potential thematic material (e.g. dramatic literature).

In German education generally there has traditionally been a clear distinction made between higher education at university, with the accent on theoretical study, and practical training; although this distinction may be said to be gradually changing. Certainly in the field of theatre and drama however,

\footnotetext{
${ }^{1}$ In den letzten Jahren hat sich der Beruf des Theaterpädagogen bzw. der Theaterpädagogin als eigenes Berufsbild entwickelt. Der Beruf des Theaterpädagogen umfasst sowohl künstlerische, als auch pädagogische Aspekte. Die Arbeitsgebiete und -schwerpunkte von Theaterpädagogen und Theaterpädagoginnen sind außerorderdentlich vielfältig und unterschiedlich, je nachdem, ob die theaterpädagogische Arbeit z.B. an einem Theater, in einem Theaterpädagogischen Zentrum (TPZ), einer Akademie, einer kommunalen, sozialen bzw. sozialpädagogischen Einrichtung oder etwa freiberuflich ausgeübt wird (www.butinfo.de).
} 
the normal situation is for theoretical work to be undertaken in university departments of theatre studies, while practical training in acting, directing and dramaturgy mostly occurs in higher education performing arts colleges. The recent developments in Theaterpädagogik perhaps represent the exception which heralds larger-scale change. In any case, the situation in the UK, for instance, is such that the borders between theory and practice at higher education level are already relatively blurred. It is possible at many universities to study for an academic degree (at both undergraduate and postgraduate levels) in practical drama, with emphases on acting, directing, stage design and others. And from the other side, many practical drama colleges now award academic degrees on completion of their courses.

Of more relevance to the current paper, however, is the deployment of practical drama within academic degrees not intended to produce professional theatre makers. This in particular has been developing considerably in the UK in recent years, to such an extent in fact that major interdisciplinary work has been carried out on researching more exactly its use and effectiveness. In English studies, this development has coincided with an ever-increasing theoretical concern with the performative in literature and language, within which context practical drama work obviously ideally fits. One of the most high-profile and comprehensive examples of this was the previously-known Capital (Creativity and Performance in Teaching and Learning) Centre at the University of Warwick. This was an initiative supported by the Higher Education Funding Council of England as a centre of excellence in teaching and learning (CETL). The work of the centre began in English and theatre studies, including collaboration with the Royal Shakespeare Company. According to centre director Carol Rutter, the main aim was to draw on rehearsal techniques from drama and theatre in order to bring in performative elements to "change the dynamic" of the higher education classroom. ${ }^{2}$ Rutter taught an early class at the centre called "Shakespeare without chairs" which focused on an "intense repertoire of close reading practices", encouraging students to "make decisions the way actors make decisions" about play text (ibid.). However, the transferable benefits of the approach were also emphasized, with Rutter herself stressing the 'real world' usefulness of rehearsal skills such as negotiation, compromise, risk-taking and experimentation.

The dual benefit of performative pedagogy, for both subject knowledge and the development of 'soft skills' applicable to many different careers, was seen in this case as a great strength of the centre; certainly no doubts seemed to arise concerning the combination of 'product' and 'process' outlooks. Indeed the centre expanded its operations to other disciplines, and soon work was being done within the medical and law schools, as well as in the departments of chemistry and philosophy. Although the centre's funding ceased in 2010, it merged with another CETL to form the Institute for Advanced Teaching and Learning at Warwick. A further project grew out of the centre, known as 'Open Space Learning' (OSL) and led by principal investigator Jonothan

\footnotetext{
2 www2.warwick.ac.uk (July 12th, 2014).
} 
Neelands. This began with the teaching of Shakespeare, and attempted to mould the approaches and outcomes into a "transdisciplinary pedagogy" (Chillington-Rutter et al. 2011). At its heart lies the combination of what Nicholas Monk has termed "mindfulness and playfulness" in learning and teaching (ibid.), based around what is referred to as the 'workshop model' of pedagogy. The physical space in which learning takes place is posited as paramount to achieving the intended equality between teacher and student, in the spirit of co-creation of knowledge ("flexible and non-hierarchical spaces that encourage collaboration"). 'Enactive' and 'kinaesthetic' learning methods are mentioned, as is a debt to applied drama/theatre/performance generally, and figures such as Boal, Paolo Freire and Lev Vygotsky specifically (ibid.).

As a summary of the current state of the art, Manfred Schewe's latest survey does not require improvements nor commentary here: he ends his comprehensive article with an exhortation towards "an increasingly differentiated understanding of the nature and quality of performative experience that can be achieved in foreign language teaching and learning" (Schewe 2013: 19).

It seems therefore that the field of drama-in-higher-education generally, and within foreign language pedagogy more specifically, has come through the initial dichotomies, via a widespread recognition of its usefulness and validity, to something of a milestone. While practical explorations will doubtless continue, how will theoretical developments move on and merge with the varied and multi-faceted nature of drama pedagogy work happening in a multitude of contexts and disciplines?

\section{Sprachpraxis at the University of Tübingen English Department}

\subsection{General background}

The English Department of the University of Tübingen, Germany, currently caters for a first semester intake of around 600 students. The department offers two undergraduate BA programmes: BA English/American Studies; BA Interdisciplinary American Studies; a teaching degree (Lehramt); and three MA programmes: MA American Studies; MA English Linguistics; MA English Literatures and Cultures. The curriculum is organized around four core areas: American Studies, English Literatures and Cultures, English Linguistics, and Academic English (Sprachpraxis). All students are required to take courses in Sprachpraxis alongside their other classes, regardless of which degree they are working towards. According to the departmental website ${ }^{3}$ :

In Academic English courses, or Sprachpraxis, you get support on de-

\footnotetext{
3 http://www.uni-tuebingen.de/fakultaeten/philosophischefakultaet/fachbereiche/neuphilologie/englisches-seminar/abteilungen/sprachpraxis.htmlc7164 (August $4^{\text {th }}$ 2014).
} 
veloping your language skills for better speaking, listening, reading and writing, as well as developing your critical thinking and reasoning skills. Our teaching is designed to make you a better, more independent learner, and one who is able to continue your learning, with or without us, in the years to come. It is based on our years of experience teaching and learning second languages, and our professional degrees in our field (of English as a Second Language and Applied Linguistics).

A key term here is "support": Sprachpraxis classes are run in parallel to seminars and lectures in the other three core curriculum areas, and are intended to offer a practical language complement to, and enrichment of, the students' academic experience. Sprachpraxis classes are further organized around three skills areas: written communication, translation, and oral communication. There is also a general Sprachpraxis course taken by all students in the first semester, Language and Use, which must be passed before taking any further practical language classes. The courses in written communication focus on the production and improvement of various forms of academic writing, with a principal aim being the development of students' written work as demanded in literary, linguistics and cultural studies courses. Translation courses focus on the development of general translation skills in the first level course, and on specific preparation for the translation task of the state exam in the second level course. Oral communication classes are focussed on the practice and development of students' spoken English, in the form of presentations, debates, and open discussion. The oral classes are arguably the least universally defined of the three Sprachpraxis areas. Given certain general curriculum requirements and assessment guidelines, individual teachers are free to choose topics and methodologies which they feel best serve the aims of the course. It is against this background that oral communication classes involving drama have been introduced.

\subsection{Three pedagogical challenges in oral communication classes}

In the two other areas of the Sprachpraxis curriculum, namely written communication and translation, the pedagogical aims are more coherently defined, with an emphasis on intended output. All students, no matter what degree type, are expected to produce academic essays, term papers and theses: this is what defines the work of the written communication classes, as mentioned above. In translation classes, students practice the specific skills and linguistic competencies required for translating from German into English; and those on the teaching degree programme currently have to prepare themselves for the translation task of the final state exam. Oral communication needs are more varied, however. For those on the English Studies degree programme, one aim is undoubtedly to practice and improve spoken academic discourse for the purpose of presentations, and at advanced levels, the delivery of conference papers. For the trainee teachers, there are additional areas of relevance: most obviously the need to develop clear, confident communication skills in order 
to teach English in schools. Furthermore there are often students from other fields, such as economics, who are taking an oral communication class as an elective, as well as students visiting from abroad on schemes like ERASMUS, all of whom may have slightly different expectations and needs from the course. For all students, the desire to develop advanced communicative competence in English might count as the one universal aim. Nonetheless, the variety of different degree types represented in the class counts as the first pedagogical challenge faced by the instructor. The second challenge is simply the size of the classes: with the vast majority of students obliged by their programmes to take an Oral Communication II course, student numbers are high: typically around 25-30 for a single class. Instructors are expected to achieve a class environment in which oral communication is actively practiced and improved, which given the typical class size can be seen as a third, related, pedagogical challenge. It is to these challenges which practical drama has been applied.

\section{Practical drama in Oral Communication II}

\subsection{The class}

Since the winter semester of $2011 / 12$, the present author has been using drama as a major component of the course type Oral Communication II at the English Department of the University of Tübingen. The course builds on the presentation skills practiced in Oral Communication I, a class typically taken by students in the second semester, and aims to introduce more complex and sophisticated communication tasks. Oral Communication II classes have a current recommended upper limit of 25 students per group. Students tend to be in later semesters, and apart from MA students, the course is obligatory at some stage for all degree types. The course in the winter semester 2013/14 consisted of a total of 30 students. Of these, 23 were on the teaching degree course, 4 were on the BA English Studies course, and 3 were MA students. The course met once a week for one-and-a-half hours.

\subsection{The concept}

One of the main ideas behind the choice of drama was its suitability, both as process and subject matter, for the students concerned (see discussion below). At this stage of their studies, most students already have sufficient language ability in English to be able to deal with more challenging, and even unfamiliar topics, which for many of them was the case with drama. Although the course fits into the general Sprachpraxis curriculum, and as such shares assessment guidelines (presentation based) with Oral Communication II classes taught by other teachers, the topic was introduced online in the course description ${ }^{4}$ :

\footnotetext{
4 http://campus.verwaltung.uni-tuebingen. de/lsfpublic/rds?state=verpublish\& status=init $\&$ vmfile=no \&publishid=103128 \&oduleCall=webInfo\&publishConfFile= webInfo\&publishSubDir=veranstaltung (August $4^{\text {th }}$ 2014).
} 
The topic of this class is applied drama. We will investigate, through practical activities and student-led sessions, how drama and theatre techniques can be applied to 'real life' situations: specifically, but not exclusively, in education. The class will therefore be of most interest to Lehramt students, but all are of course welcome. No previous experience of drama is necessary, but students will be required to participate actively in drama exercises throughout the semester!

The choice of applied drama, but not necessarily drama-in-education exclusively, was in anticipation of the different degree types represented in the class group. However, as the majority of students were indeed on the teacher training degree programme, the emphasis ended up being more on drama-in-education than on any other area of applied drama. After reading the class description many students registered because of an existing interest and/or experience in drama; many however attended with no pre-knowledge.

The first week involved an introduction to the work of the semester, including the assessment, and to applied drama generally. An introductory text was provided for the students to read for discussion the following week: the chapter on applied theatre from The Cambridge Introduction to Theatre Studies by Christopher Balme (2008). Weeks 2-5 consisted of teacher-led practical drama sessions, each focusing on a general area of drama practice:

- Week 2: Non-verbal exercises (group formation, physical games, mime, frozen images)

- Week 3: Verbal exercises (vocal warm-ups, words games, small group scenes)

- Week 4: Improvisation (shorter games and longer-form exercises)

- Week 5: Text-based (contrasting modern and classical texts)

For the rest of the semester, the classes were devoted to student-led assessed sessions, followed by peer feedback. Sessions mostly focused on an aspect of one of the areas worked on in weeks $2-5$, but this was not obligatory. The sessions, of between 45 and 60 minutes, were led by groups of three students, and had to investigate an area of applied drama. After the introductory teacher-led sessions, and being provided with a suggested reading list, students had to find and research their own topic within the field of applied/educational drama. Rather than being simply presentations, the sessions had to actively involve the class, either in discussion of the ideas or in practical drama-based exercises. Assessment criteria were language correctness, communicative effectiveness, class interaction and thematic focus. The topics chosen by the students in the winter semester 2013/14 were:

- Theatre pedagogy for teachers 
- Drama therapy

- Improvisation for second-language-learning

- Scene-work in class

- Improvisation for general professional development

- Bi-lingual comparison of text-based and improvised drama

- Improvisation as a rehearsal tool

- Drama for intercultural communicative competence

- Drama for teacher training

- Drama for voice development

\section{Example session: Bi-lingual comparison of text-based and improvised drama}

The aim of this session was to stage contrastive dramatic performances (textbased and improvised) in German and English, and to survey the students' opinions on the results. The performance groups were assembled randomly, by drawing cards, and assigned one of the following categories:

1. Improvisation group in English

2. Text-based group in English

3. Improvisation group in German

4. Text-based group in German

The text chosen for the text-based groups was The Breakfast Police by Nicholas Richards; the German version was a translation of the original by one of the three presenters. The groups left the room, and were independently told of their tasks: the text-based groups were issued their texts, while the improvisation groups were given the basic situation to be improvised (three generations of a family sitting in an airplane waiting to take off to a holiday destination). The text groups had twenty minutes to prepare their work, while the improvisation groups performed. None of the performance groups saw any of the other groups perform. The rest of the class were issued questionnaires with the following list of categories, with which they had to evaluate the performances on a scale from 1 (very good) to 5 (very poor):

1. Language 
- Fluency

- Grammar

- Articulation

- Volume

- Vocabulary

- Pronunciation

- Intonation

2. Performance

- Believability

- Enthusiasm

- Body Language

- Facial Expression

- Comprehension

- Confidence

Students were also given space to write down any general comments they had about the different performances. The reliability of this peer assessment was at least partly ensured by the questionnaire, and the consistency of the rater group (22 people): none of the raters took part in any form of performance during the entire session; their job was simply to watch and reflect on the performances.

In the final discussion, the presenters mentioned that they had expected both language and performance evaluation criteria to be rated much higher in the German groups than the English groups. It emerged however that the vast majority of the class felt that there had been no major difference in the overall performance effectiveness as represented by the six evaluation indicators on the questionnaire. Indeed this was borne out by the analysis of the data provided some weeks later by the presenters, in which they compressed the average scores for each criterion into two graphs, one for the language categories and one for the performance categories, across all four groups:

The differences in language criteria were to be expected, as all of the students spoke German as a first language. It is noteworthy that while more specific paralinguistic criteria like articulation, pronunciation and intonation had the biggest discrepancies between the languages, the criterion perhaps most related to overall communicative effectiveness - fluency - showed the smallest difference. More surprising however were the differences displayed 


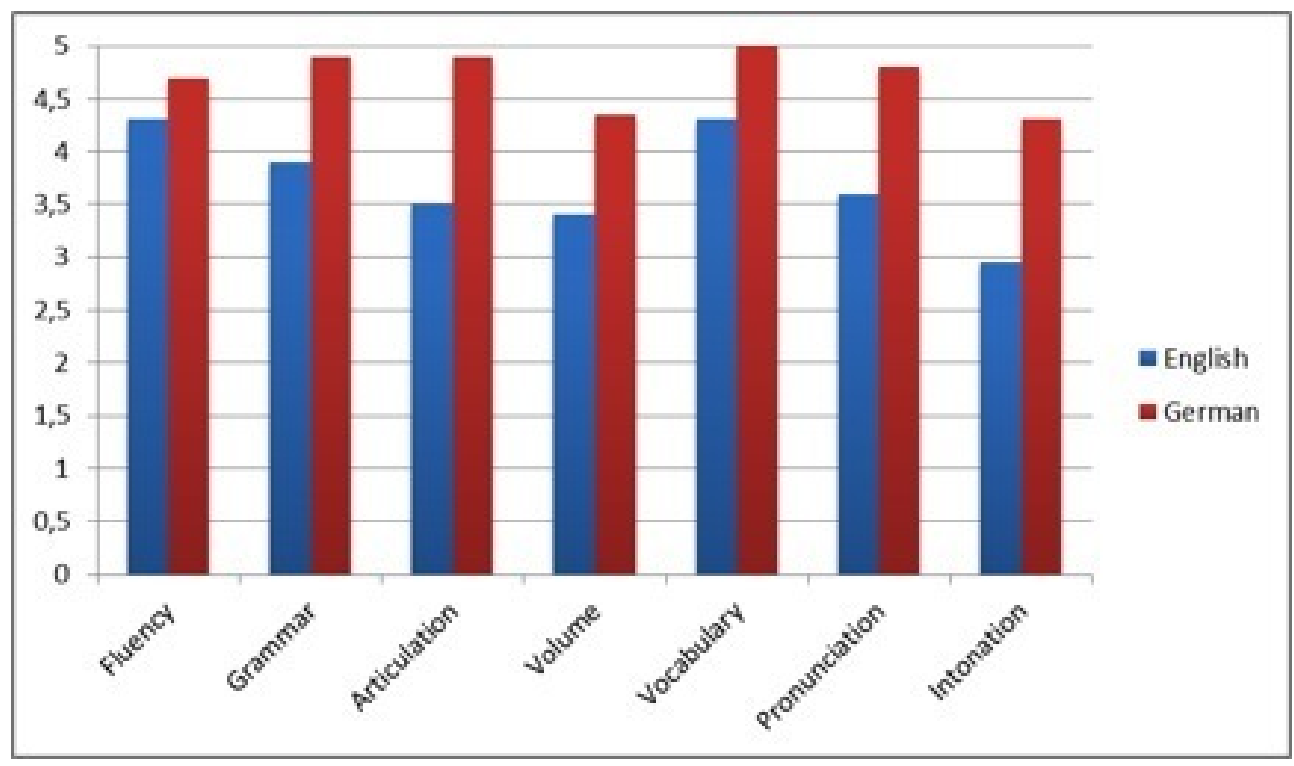

Figure 2: Language Graph.

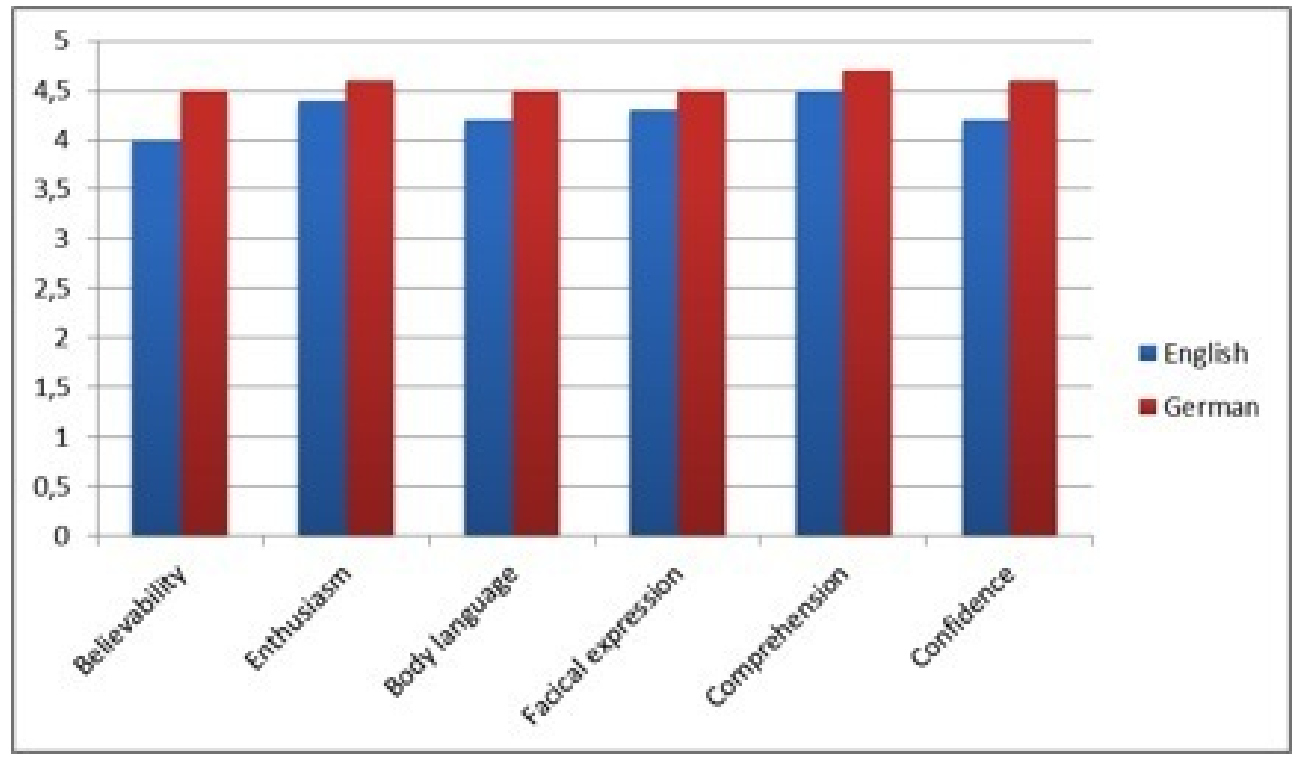

Figure 3: Performance Graph. 
in the performance category. Here the single biggest discrepancy was in believability, and even then it was only a difference of 0,5 of an evaluation point. Differences in the categories of comprehension, facial expression, and perhaps less surprisingly enthusiasm, were negligibly small between the languages. The results, although not in any way intended to be offered as significant findings, would indicate that despite differences in linguistic ability and effectiveness, the performance quality and overall communicative success of the groups was not greatly affected by the language. While clearly not a new notion, the greatest effect of this on the class was the fact of this small experiment having been carried out and analyzed by members of the class themselves, all of them students of education, and the findings presented to and discussed with the rest of the group.

\section{Student reactions}

At the end of the semester, the students were given the opportunity to provide written feedback on the class. They were asked for their overall impressions of the course, how useful and enjoyable they had found it, and also about any particular difficulties or challenges they were experiencing in the practical curriculum areas of their studies of English. 26 of the 30 students provided this written feedback.

The most frequent comment, made by 19 of the respondents, was that they had found the class positive in terms of providing a platform for spontaneous, 'authentic' spoken language practice. The second most frequent comments, each made by 11 of the respondents, were that they had found the course practically relevant to their future careers, and that they had welcomed the practical approach as a contrast to the theoretical basis of most of their other classes. The third most frequent comment, made by 8 of the 26 respondents, was that they had been unsure of the approach at first: adjectives used in these comments included "scared", "nervous" and "unsure". In all 8 cases, the respondents reported that they had experienced a positive change in attitude as the semester progressed and they got used to the work. The next most frequent answers given were that the class had helped the students to develop their general communicative confidence and teamwork abilities ( 7 respondents each).

In the section on particular difficulties in practical English classes at university, the top response, made by 9 of the 26, was finding opportunities to practice spoken English in 'no pressure' situations, free of fear of making mistakes. The second top response, made by 3 of the 26, was finding classes with topics relevant to their future careers.

The overall impression was that the students had overwhelmingly positive opinions of the class. Some made specific observations that such courses should be offered more:

“This was great! Courses like this should be available much more, es- 
pecially for Lehramt students. This class was new and fresh and really involved us."

It would appear, from the limited data collected, that there is a clear correlation between what students see as challenging, i.e. opportunities for 'no pressure' oral practice and finding career-relevant classes in Sprachpraxis, and the most frequent responses to the class, i.e. that it had indeed provided such a platform for informal, 'authentic' oral practice, as well as being highly relevant for their future careers, mostly as teachers. So thus far it does indeed seem that practical drama within the Sprachpraxis curriculum has been positively received by students, with a desire for its continuance.

\section{Relevance of drama in Sprachpraxis oral communication classes}

From the perspective of the instructor, the choice of practical drama as both method and theme (DiE) offered effective solutions to the three pedagogical challenges outlined above. In terms of serving the various degree types within the class, applied drama as a semester topic could be adapted to different degree-relevant interests. Students not on the teacher training degree programme could focus on drama for professional communication development or on working with the class on scenes from plays, while the teacher training degree students, who were in the clear majority, could work on and present specific areas of career-relevant drama-in-education (see presentation topics above). This allowed the groups to concentrate on areas of interest while also having freedom in their approaches to the topics: some opted for a deeper investigation of theoretical elements, while others centred their sessions on a more practical 'training' approach, based on either linguistic or pedagogical elements. The class feedback also indicated that the drama approach had positively addressed some of the common needs and desires which the students themselves had identified as relevant to the oral communication elements of their studies.

\section{Conclusions and future possibilities}

Given both the positive outcome of the drama approach to the pedagogical challenges faced by the teacher in Sprachpraxis oral communication classes at Tübingen, and the overwhelmingly positive reactions of the students, particularly given that the drama approach seemed to offer solutions to some commonly held concerns, it seems reasonable to argue that further such classes should be available within the university curriculum. This raises many other issues of course, including how such classes might be further adapted to offer various drama-based options; how they might be assessed; and whether specialist training could be offered to staff in how to use drama techniques in their 
teaching. In the current semester (summer 2014), the present author has now extended the scope of practical drama, piloting a second Oral Communication II course, this time based more exclusively on performance. The first part of the semester offers 'performance training' sessions, including physical, vocal, improvisational, text analysis and characterization components. Towards the end of the semester, assessment sessions will take place, this time with the requirement that a performance of some kind must occur. In this way, students are getting close to becoming actors and directors in the language classroom, which leads to the question of how to disentangle the language elements necessary for assessment from the inevitable focus on dramatic performance, without necessarily assessing the performance as a whole; the question indeed of whether such a distinction is necessary is of course also pertinent. I would suggest that, in the spirit of moving towards the "performative teaching and learning culture" indicated by Manfred Schewe (Schewe 2013), assimilation rather than clear-cut distinction would be both desirable and productive. Another future plan is to extend the offer from in-class "small-scale forms" (e.g. class-length exercises, games and shorter scenes) to also include "large-scale forms" (e.g. longer projects extending for an entire semester, full productions) (Schewe 2013: 13-14). A longer project based on Macbeth has just been launched (May 2014) to coincide with the two Shakespeare anniversary years of 2014 and 2016: a year-long theatre-in-education project including practical classes on the play and culminating in a full production cycle, with rehearsals and performances taking place in the Brechtbautheater, Tübingen, in summer 2015. Process drama in this case will be utilized not only to train and perform with a non-native speaking cast, but also to 'train' the audience which will see the final production.

The issue of specialist training in drama-based pedagogy for staff is more difficult to address, and is perhaps more reliant on institutional and organizational coherence than the initiative of individual teachers. In Germany the presence and profile of Theaterpädgogik is increasing dramatically. In Baden-Württemberg alone there are training institutions in Stuttgart, Heidelberg, Reutlingen, Aalen, Freiburg, Lörrach and Oberspitzenbach listed on the website of the Bundesverband Theaterpädagogik E.V. (German Theatre Pedagogy Association). ${ }^{5}$ Although the full training as a Theaterpädagogin has not yet received state recognition, the Bundesverband strives to ensure that there are consistent standards across all institutions, with the highest final qualification of Theaterpädagoge/in BuT® having been available since October 1999. In addition, the association and its partner institutions offer short training courses and workshops for educators wishing to learn the basics. The presence of Theaterpädagogik is also growing at degree level, with bachelors and masters degrees available at more and more colleges and universities throughout the country.

The greatest advantage of the practical drama approach to teaching within a Sprachpraxis curriculum is perhaps its flexibility, however; and a

\footnotetext{
5 http://www. butinfo.de (July 23rd 2014).
} 
rigorous adherence to the principles of any one organization, no matter how commendable, might not necessarily be the most sensible approach. In the spirit of the experimentation and creativity we demand of our students, we might indeed focus on the performative in language teaching as the "umbrella term" (Schewe 2013: 18) which covers a multitude of practices, backgrounds and approaches.

\section{Bibliography}

Balme, Christopher (2008): The Cambridge Introduction to Theatre Studies. Cambridge: Cambridge University Press

Boal, Augusto (1985): Theatre of the Oppressed. New York: TGC

Boal, Augusto (2002): Games for Actors and Non-Actors. New York: Routledge

Bolton, Gavin (1979): Towards a Theory of Drama in Education. London: Longman

Chillington-Rutter, Carol; Heron, Jonathan; Monk, Nicholas; Neelands, Jonothan (2011): Open-Space Learning: A Study in Transdisciplinary Pedagogy. London: Bloomsbury

Fleming, Michael (1998): Cultural awareness and dramatic art forms. In: Byram, Michael; Fleming, Michael (eds): Language Learning in Intercultural Perspective: Approaches through drama and ethnography. Cambridge: Cambridge University Press

Fonio, Fillipo \& Genicot, Genevie `ve (2011): The Compatibility of Drama Language Teaching and CEFR Objectives. Observations on a Rationale for an Artistic Approach to Foreign Language Teaching at an Academic Level. In: Scenario V/2, 75-89

Haack, Adrian (2010): KünstlerInnen der improvisierten Aufführung. Performative Fremdsprachendidaktik als Teil des Lehramtsstudiums. In: Scenario IV/1, 35-53

Haack, Adrian \& Carola Surkamp (2011): ,Theatermachen“ inszenieren. Dramapädagogische Methoden in der Lehrerbildung. In: Küppers, Almut, Torben Schmidt \& Maik Walter (eds.) (2011): Inszenierungen im Fremdsprachenunterricht. Grundlagen, Formen, Perspektiven. Braunschweig: Diesterweg, 53-67

Hornbrook, David (1998): Education and Dramatic Art. London: Routledge Monk, Nicholas: Interview

(http://www2.warwick.ac.uk/fac/cross_fac/capital/teaching_and_ learning/materials/conversations/nickandjonny.mp4)

Prendergast, Monica; Saxton Juliana (2013): Applied Drama. Bristol: Intellect

Rutter, Carol: Interview (http://www2.warwick.ac.uk/fac/cross_fac/ capital/lightbox/player.swf?url=http: //www2.warwick.ac.uk/fac/cross_fac/capital/001overview_1.flv) 
Schewe, Manfred (2013): Taking stock and looking ahead: Drama Pedagogy as a Gateway to a Performative Teaching and Learning Culture. In: Scenario VII/1, 5-28

Wildt, Beatrix, Ingrid Hentschel \& Johannes Wildt (eds.) (2008): Theater in der Lehre. Verfahren, Konzepte, Vorschläge. Berlin/Zürich: LIT

Woodward, Tessa (2003): Key Concepts in ELT: Loop Input. In: ELT Journal $57 / 3,301-304$

http://www . butinfo.de (July $23^{\text {rd } 2014)}$

http://www. uni-tuebingen. de (August $4^{\text {th }}$ 2014)

http://www2.warwick.ac.uk/fac/cross_fac/capital/ (July $12^{\text {th }} 2014$ )

http://www2.warwick.ac.uk/fac/cross_fac/iatl/(July 12 th 2014)

Open-space learning: http://www2.warwick.ac.uk/fac/cross_fac/iatl/ activities/projects/osl-final/ (July $12^{\text {th }}$ 2014) Internet links: 